\section{Questión}

Periodismo / Comunicación ISSN 1669-6581
- Av. $44 \mathrm{~N}^{\circ} 676,1^{\circ}$ piso

CP 1900 - La Plata - Argentina

www.perio.unlp.edu.ar/question

Alambrados y alicates: la pandemia como oportunidad para ampliar las excepciones al derecho de autor en Argentina

Miriam Socolovsky

DOI: https://doi.org/10.24215/16696581e304

\title{
Alambrados y alicates: la pandemia como oportunidad para ampliar las excepciones al derecho de autor en Argentina
}

\section{Wires and pliers: pandemic as an opportunity to expand copyright exceptions in Argentina}

Miriam Socolovsky / miriamsoco@gmail.com

Santa Rosa, La Pampa (1977). Lleva algunos años trabajando como coordinadora editorial del IEC-CONADU, unos cuantos más como docente en la UNLP y casi toda la vida militando. De a ratos ha sido gestora de espacios culturales,

librera y guionista de historietas.

Alimentando al mogwai

El encuentro tiene lugar, claro está, por Zoom. Algunas decenas de docentes universitaries asistimos a una capacitación para trabajar en entornos virtuales y poder empezar el ciclo lectivo sin encuentros presenciales. Hay muches que aún piensan que el distanciamiento preventivo va a durar dos o tres semanas y que enseguida volveremos a la normalidad. La charla aborda consejos para no aburrir a les estudiantes y se brinda información sobre algunas plataformas de trabajo. De pronto cae el aviso:

- Nunca, pero nunca, difundan obras sin permiso del autor o del que tenga los derechos. La capacitadora insiste; la advertencia resuena como si todes, en nuestros hogares, tuviéramos un mogwai al que estamos por alimentar después de la medianoche. En lugar de gremlins, el animalejo escupirá demandas judiciales y, por qué no, algún allanamiento, incluso una 
temporada en la prisión. Al fin de cuentas, la ley de Propiedad Intelectual vigente en la Argentina impone muchísimas restricciones y habilita pocas excepciones.

Advierto el gesto dubitativo en otres docentes: ¿qué hacer, entonces? ¿Por qué, si a nadie parece importarle que en una clase proyectemos una copia de El Padrino que bajamos de torrents o que fotocopiemos un cuento para trabajar con nuestros estudiantes, ahora nos advierten sobre el peso de una ley que existe desde 1933? ¿Acaso las posibilidades de digitalizar contenidos y compartirlos por internet no deberían dar cuenta de condiciones más propicias para el acceso a la producción cultural? ¿Tenemos que decirles a nuestros alumnes que se arreglen con lo que tienen en su casa, pensión, o donde sea que estén pasando la cuarentena?

Estamos atrapados en la misma red

Cantaba el Martín Fierro que la ley es tela de araña: en el caso de la 11.723, que rige la propiedad intelectual en nuestro país, más que una trama pegajosa, encontramos una sucesión de cadenas: así de duras son las condiciones que impone desde hace casi noventa años. Y se cumple, a rajatabla, el precepto de que "la rompe el bicho grande y sólo enreda a los chicos". No distingue usos con fines de lucro de usos no lucrativos; ni situaciones educativas o de democratización cultural de otros contextos y, en una misma red que pertenece al fuero penal, quedamos enredados educadores, bibliotecarios y archivistas, y las y los usuarios de estos ámbitos.

La práctica docente está atravesada por una permanente y necesaria ruptura con esa ley: de atenernos a ella, cada une de nuestros estudiantes debería recurrir únicamente a libros comprados por ellos mismos (porque el préstamo entre particulares está prohibido) o esperar a que la biblioteca de la institución en la que estudian lo tenga. Deberían hacerlo siempre, sin importar si el libro va a ser usado en su totalidad o en unas pocas páginas; ni tampoco si se trata de una edición disponible o agotada hace mucho tiempo. Las posibilidades de usar otro tipo de obras (musicales, audiovisuales, pictóricas, fotográficas) no son mayores: ¿Armar un trabajo práctico que consista en adaptar una obra musical con menos de setenta años de publicada? ¿Proporcionar copias digitales de una fotografía para ejercitar una consigna a partir de la misma? ¿Copiar una película de un DVD que alguna vez compró el docente y pasarla a mp4 para verla y analizarla con los estudiantes? ¿Tomar los cuentos de un autor consagrado y 
hacer historietas a partir de ellos? No, no, no y no. Tal vez no sean los autores los que reclamen, ya que con frecuencia están muertos, pero pueden reclamar sus herederos. O, lo más común, las sociedades de gestión colectiva y los oligopolios de la cultura.

A pesar de la rigidez de la ley existente y de las escasísimas excepciones que contempla, es habitual que docentes y estudiantes nos manejemos con otro criterio: el de priorizar lo que la situación educativa requiere para resolverse de la mejor manera posible. Eso suele hacerse sin que se interpongan demandas ni procesos penales. En mis veintidós años como docente universitaria, nunca antes había recibido una advertencia al respecto. La pregunta obligada es en qué modifica la pandemia estas prácticas, si debería hacerlo y si, acaso, no debería ser ésta una oportunidad para repensar al derecho de autor en relación con otros derechos.

Piratas, no: bandoleros, y a mucha honra

En 1999, Horacio Potel, profesor de Filosofía de la Universidad Nacional de Lanús, decidió hacer algo para subsanar la falta de disponibilidad de traducciones al castellano de los libros de Jacques Derrida, Friedrich Nietzsche y Martin Heidegger. Creó sitios web para cada uno de estos autores y subió textos que de otra forma hubieran permanecido inaccesibles para sus estudiantes y colegas. A pesar del evidente fin educativo de la actividad y de que no había ningún lucro ni remuneración por la misma, la Cámara Argentina del Libro inició acciones legales y en el año 2008, Potel sufrió un allanamiento y terminó en la cárcel. Lo sobreseyeron en el 2009: sin embargo, nada de esto alteró el articulado de la 11.723.i

El caso de Potel puso de manifiesto que, ante los cambios en los modos de compartir materiales que son posibles a partir de la expansión de los medios digitales y la aparición de soportes, formatos y dispositivos inexistentes cuando se redactó la ley, las entidades recaudadoras de regalías aprovechan para extender sus alcances y restringir aún más la circulación de la producción cultural. En esta pandemia ven la posibilidad de pedir más vigilancia: en las últimas semanas, hemos tenido más artículos periodísticos sobre cantidades y tipos de obras descargadas ilegalmente (y sus supuestos efectos devastadores) que las que hayamos podido leer o escuchar en mucho tiempo.

La denominación "piratería" para la práctica de obtener y hacer circular producciones culturales en formas no habilitadas por la ley cuando el fin es educativo o de investigación es, cuanto menos, ingrata e injusta. Una docente que fotocopia un cuento para dar una clase de literatura 
no está robando nada, está trabajando en la generación de un público lector que -muy probablemente- no tenga esos libros en sus casas y que a partir de esas clases, tal vez empiece a buscar los libros del mismo autor en bibliotecas o a comprarlos, en la medida en que pueda hacerlo. Si no hay rédito económico no deberíamos hablar de piratería. En todo caso, y en términos simbólicos, el acto de obtener un recurso para repartirlo entre quienes necesitan de él nos pone a todas y todos los que incidimos en esa práctica más cerca de Robin Hood o de Mate Cosido que de Henry Morgan.

Limitaciones y excepciones: más allá de la pandemia

A principios de abril, más de cien organizaciones e individuos (entre ellas, la Internacional de la Educación, asociaciones de bibliotecarios de diferentes países, y organizaciones como Wikimedia y Creative Commons) reclamaron a la Organización Mundial de Propiedad Intelectual (OMPI) que tome medidas para instar a sus países miembros a levantar las restricciones que obstaculizan el acceso a recursos educativos, culturales y de investigación "para ayudar a afrontar la pandemia global así como para minimizar la disrupción causada por la misma".ii En sintonía con ese pedido, el G BAIPI (Grupo Bibliotecario sobre Acceso a la Información y Propiedad Intelectual) está pidiendo que se implemente en la Argentina un proyecto para liberar las obras bajo derecho de autor "por el tiempo que dure la pandemia para que sean utilizados por bibliotecas, museos, archivos, instituciones, centros y establecimientos científicos, culturales, artísticos y de enseñanza del país".iii Dichas peticiones coinciden con la liberación momentánea de numerosas obras (literarias, audiovisuales, teatrales, etcétera) que se hallan disponibles mientras siga la cuarentena o que levantan las restricciones por unos días, como forma de conmemorar determinados acontecimientos desde el distanciamiento (por ejemplo, para el 24 de marzo, el 2 de abril, el 1 de mayo).

Pero, incluso si debido a la pandemia se lograra la habilitación para acceder a todos los materiales que se están reclamando, ¿qué sucederá cuando se pueda volver a las aulas, a las bibliotecas, a los archivos y a tantos otros espacios que en este momento están cerrados? ¿Seguirá inconmovible la letra de la 11.723 ?

El reclamo de limitaciones y excepciones a la ley de propiedad intelectual para situaciones educativas, bibliotecas y archivos no surge de la pandemia. La reivindicación del derecho a la educación y a la cultura como cuestiones prioritarias que deben primar por encima de los 
intereses individuales y del lucro de los privadosiv tiene años en circulación y ha llevado incontables acciones de diversas organizaciones, como las firmantes de la carta a la OMPI.

Esta debería ser una oportunidad para poner en discusión un régimen repleto de paradojas. Un régimen según el cual, por ejemplo, una productora que filmó una película con un subsidio del Estado argentino puede reclamar que le paguen por usar ese material en una institución educativa sostenida por el mismo Estado que ayudó a financiar la obra. Un régimen que impone que estudiantes de todos los niveles no puedan acceder a más recursos que los que les habilitan los oligopolios de la cultura y las sociedades de gestión colectiva. Un régimen que obstaculiza la generación de un público para las obras. Un régimen que plantea un falso enfrentamiento entre autores y lectores mientras el elefante que se lleva las ganancias (llámese Pearson, Bertelsmann o Planeta) se oculta detrás de la biblioteca.

\footnotetext{
i Para más detalles, ver: https://medium.com/@pazpena/muri\%C3\%B3-el-primer-pirata-adi\%C3\%B3s-a-horacio-potelc41778f01bbd

ii El texto completo de la carta puede leerse aquí: https://iec.conadu.org.ar/files/areas-de-trabajo/1587744161_carta-ala-ompi-castellano.pdf

iii Se puede ver el texto completo del petitorio y la invitación a firmar desde:

https://www.facebook.com/permalink.php?story fbid=2899672840118353\&id=247391388679858

iv Al respecto, recomiendo Propiedad intelectual y derechos humanos, de Beatriz Busaniche:

https://www.vialibre.org.ar/wp-content/uploads/2016/04/piydh_busaniche.pdf
} 